\title{
Primary Modified Blair Arthrodesis for Group-III Hawkins Fracture-Dislocation: A Series of Five Cases
}

\author{
by Arunangsu Bhattacharyya, MS(Ortho $)^{1 凹}$, Dibyendu Biswas, MS(Ortho $)^{2}{ }^{\bigotimes}$, Rajat Ghosh,M.B.B.S. ${ }^{3}$
}

The Foot and Ankle Online Journal 3 (10): 1

Background: Fracture of the neck of the talus with dislocation of talo-tibial joint and subtalar joint might be one of the worst injuries that can happen around the ankle joint. Almost all cases are complicated with avascular necrosis of the body of the talus and takes years to be revascularized even after prolonged non weight bearing. Different types of arthrodesis has been advocated by several authors. In the reported series, Blair fusion is the opted procedure because of several merits.

Methods and Material: Five patients with Hawkins Group III were selected in this series. (4 male, 1 female) One patient had compound fracture-dislocation. They were treated with Blair arthrodesis and followed up for more than two years with serial radiographs and assessment of tibiopedal movement.

Results: Three patients (60\%) recovered with excellent result with range of Tibiopedal movement was 15 to 20 degrees and it was painless and one had good result (20\%) with occasional pain and range of movement was 10 to 15 degrees. One patient had pain on walking and the outcome was graded as poor (20\%) and range of movement was less than 10 degrees. Heel shape and heel height were maintained after surgery.

Conclusions: Blair fusion may be recommended as it is a relatively easy way out of a complex problem around the ankle. Remained tibiopedal movement helps the patient to walk more physiologically.

Key words: Fracture talar neck, Hawkins fracture-dislocation, Dislocation of body, Primary Modified Blair fusion, arthrodesis.

This is an Open Access article distributed under the terms of the Creative Commons Attribution License. It permits unrestricted use, distribution, and reproduction in any medium, provided the original work is properly cited. (The Foot and Ankle Online Journal (www.faoj.org)

$\mathrm{F}$ racture of the neck and the body of the talus is one of the most devastating injuries around the ankle. Fractures are very often complicated with dislocation of talo-navicular or subtalar or talotibial joint.

\footnotetext{
Address correspondence to: Dr Arunangsu Bhattacharyya,MS(ORTHO) A-8/4,Bidhan Abasan,Block-FB,Sector-3,Saltlake,Kolkata-700097.West Bengal,India. Email: orthoarunangsu@yahoo.com

${ }^{1}$ Assistant Professor. ,Dept. of Orthopaedics, Medical College,Kolkata.

${ }^{2}$ Assistant Professor, Dept. Of Orthopaedics, North Bengal Medical College \& Hospital,West Bengal.

${ }^{3}$.Medical Officer. North Bengal Medical College \& Hospital.
}

Fractures that create difficulty in management are fractures of the talar neck with or without dislocation; dislocations of the body of the talus; and fractures with loss of a segment of the body of the talus because those are commonly complicated with avascular necrosis of the talus. There are different opinions on suitable treatment of this type of injury. Talar neck fracture and talar body dislocation can occur due to forced dorsiflexion of the talus against the anterior edge of the tibia. Non-displaced fracture of the body of the talus, subtalar or talonavicular subluxation or dislocation can be treated with closed manipulation and plastering. 


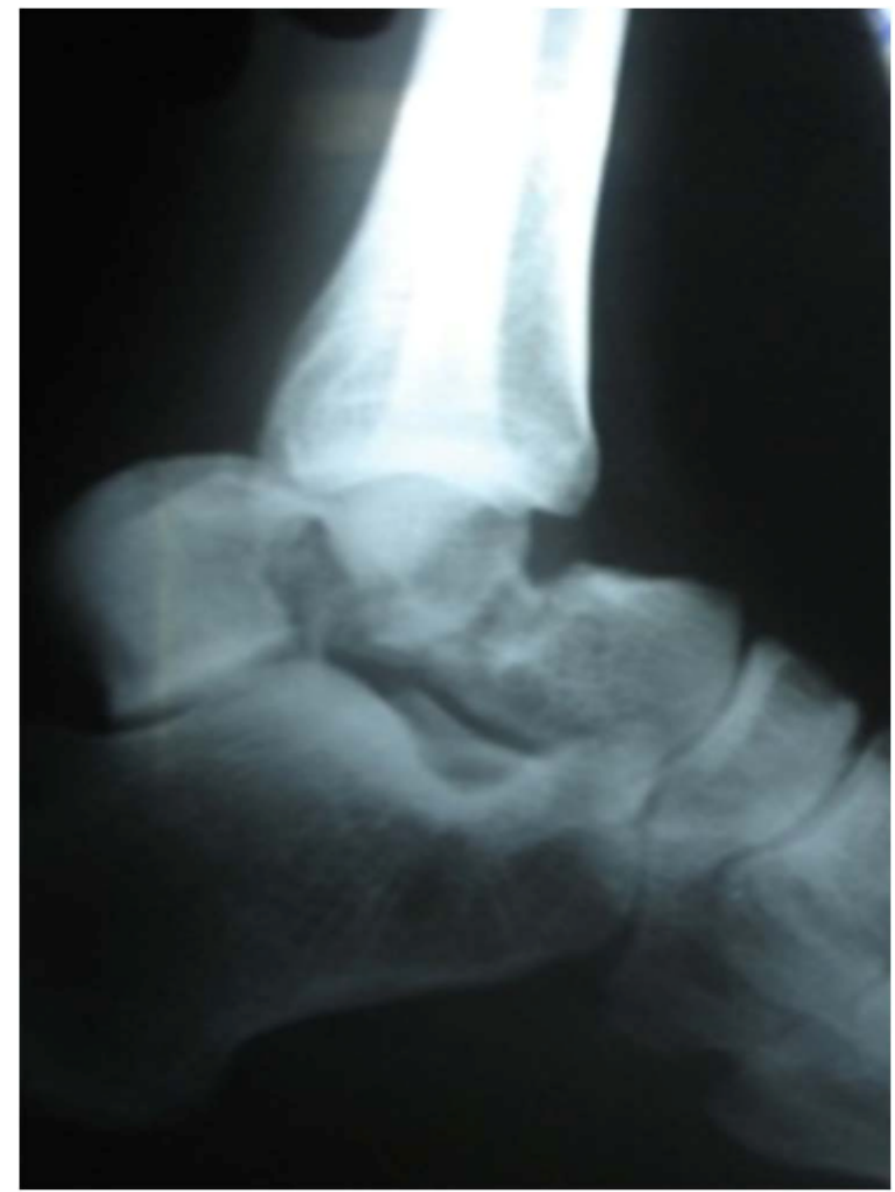

Figure 1 Example 1 - Case 1 (see table 1): Fracture of the neck of the talus with dislocation of the body (i.e. Group -3, Hawkins fracture with no neurovascular deficit.)

In 1939, Miller and Baker recommended subtalar or pantalar fusion for the fractures with poor reductions. ${ }^{1}$ Triple or subtalar arthrodesis as treatment of improperly reduced fracture dislocation of talus was suggested by Schrock, et al.,. ${ }^{2}$

In 1943, Blair described a type of tibiotalar fusion in which the body of the talus was excised and a sliding cortical bone graft was positioned between the anterior aspects of the tibia and the head of the talus. ${ }^{3}$

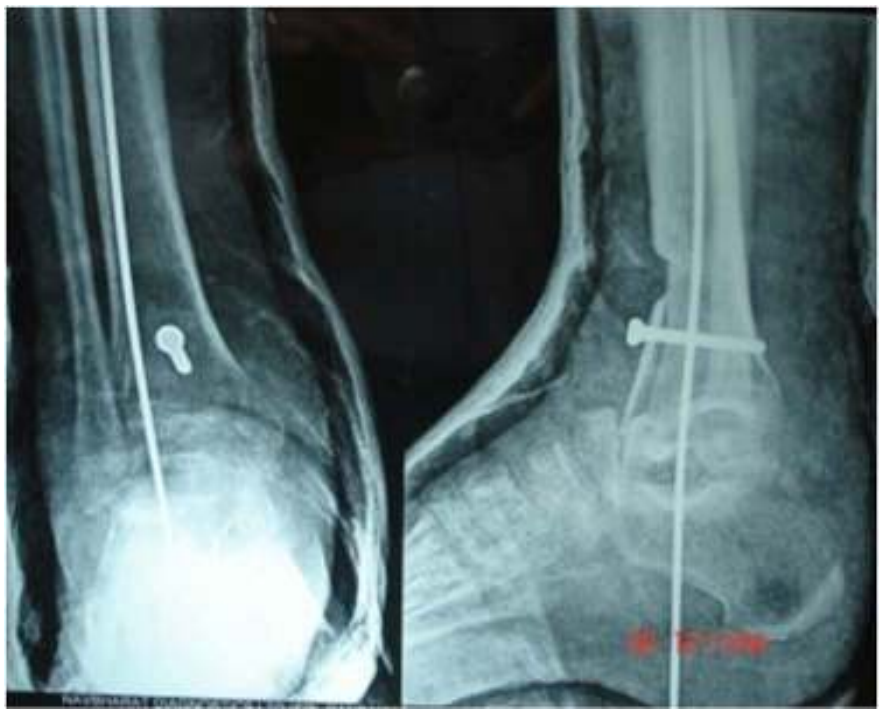

Figure 2 Example 1 - Case 1: Radiograph shows that the talar body was excised and Ankle fused with a $2.5 \mathrm{~mm} \mathrm{~K}$-wire and a $4.5 \mathrm{~mm}$ cortical screw, passed through a sliding tibial graft and up to posterior cortex of tibia. (Modified Blair fusion)

In 1969, Detenbeck and Kelley recommended talectomy and tibiocalcaneal compression arthrodesis as the primary treatment for fracture-dislocation of the talus. They reported no significant functional disability after this procedure, but it has the disadvantages of widening the hind part of the foot and shortening the foot, both of which make shoe fitting difficult. ${ }^{4}$

In 1970, Hawkins proposed a very useful classification of talar neck fractures. In Group I, the vertical fracture of the neck must be undisplaced. In Group II, the fracture is displaced and the subtalar joint is subluxated or dislocated, and the ankle joint normal. In Group III, the fracture fragments are displaced and the body of the talus is dislocated from both the ankle and subtalar joints. ${ }^{5}$ Incidence of avascular necrosis of body of talus is different in each type. 


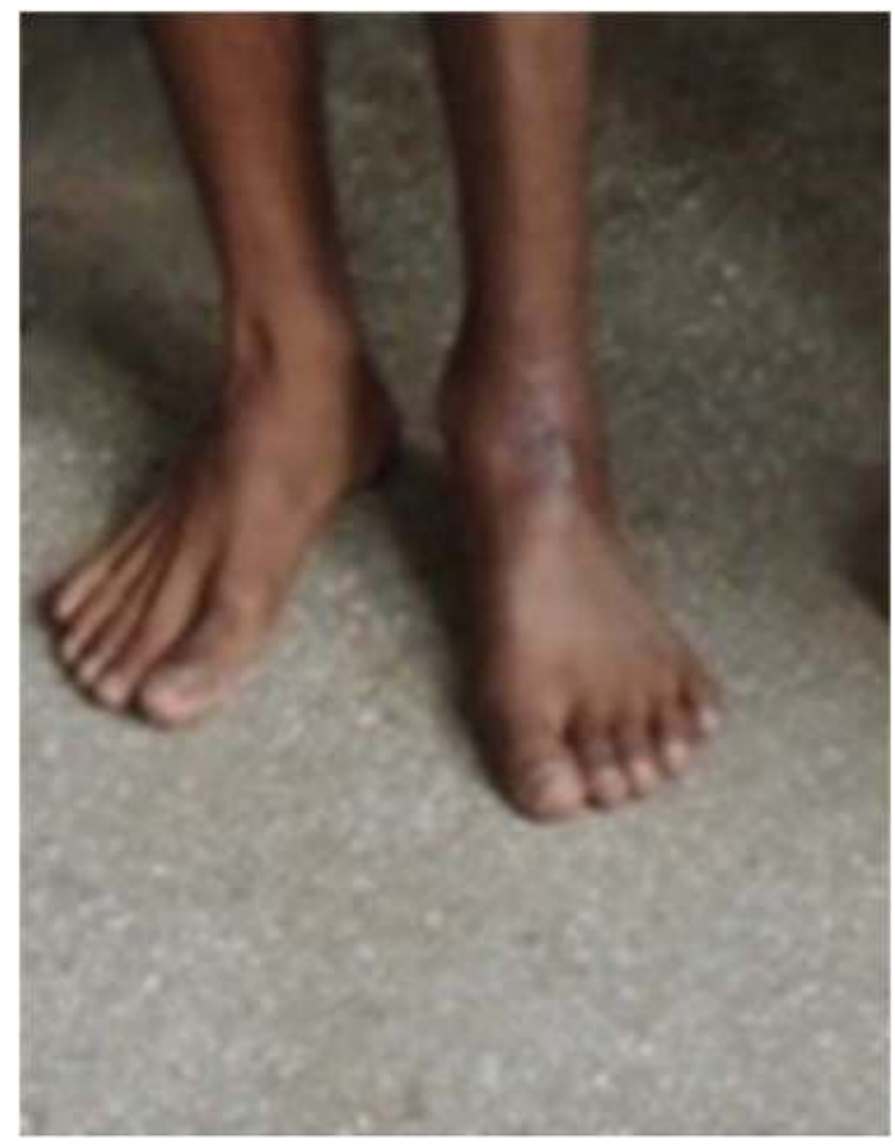

Figure 3 Example 1 - Case 1: The patient now stands on the floor with both feet on the ground and shape of left foot is well maintained after Modified Blair fusion.

Group I undisplaced fractures of talar neck are usually not complicated with avascular necrosis. ${ }^{5,6,7}$ Fractures of the neck associated with subtalar subluxation or dislocation had an incidence of avascular necrosis of 36 per cent in Kenwright and Taylor's series. ${ }^{7} \quad$ Hawkins series acknowledged avascular necrosis in 42 per cent of his Group-II fracture-dislocations, but union of the fracture took place in all. Incidence of avascular necrosis in Group III fracture-dislocation ranges from $75^{7}$ to $100^{8}$ per cent. According to Watson-Jones avascular necrosis is almost inevitable in fractures of the talar neck with dislocation of the body. So avascular necrosis following fracture of the neck of the talus is a very common incidence, hence, it is a challenging subject for the orthopaedic or podiatric surgeon.
Harry D. Morris and associates, in1971, did modify Blair method of tibio-talar fusion and added a cortical screw through the graft up to posterior cortex of the distal end of the tibia and a Steinmann pin through calcaneus into the Tibia to stabilize the Ankle. 'The present paper reports five almost such operations with follow-up of two years. In this series part of the body of talus was not excised. It was positioned in between calcaneus and tibia with cancellous bone graft taken from bed of sliding cortical graft with the idea that inter positioned cortical and cancellous bone would make sound ankylosis of ankle with maintenance of heel height.

This reported series has shown the results of the treatment of five cases of fracture of talar neck with dislocation of body after primary Blair's method of fusion modified by Morris, et al,. Cases were followed up for more than two years.

\section{Subjects and Methods}

In our series, five cases with fracture of the neck of the talus with talar body dislocation were included. It was of Group III according to Hawkins classification. Study was conducted from the year 2006 to 2010. (i.e. for four years) Out of five patients, four were male and one was female. Median age was approximately thirty years. (range $24-40$ years) Right ankle was injured in four cases. Median follow-up was up to 28.6 months. (range $24-35$ months) In one case, the fracture was of compound type. Initially wound was debrided and sensitive intravenous antibiotic continued for two weeks before final surgery. (i.e. tibio-talar fusion)

Primary Blair fusion modified after Morris, et al., was the preferred option in the reported series. Ethical committee permission was taken for this study.

In all cases, surgery was delayed routinely to provide time for swelling to subside. Absence or reduction of swelling helped to do thorough, meticulous dissection along the tissue planes. 


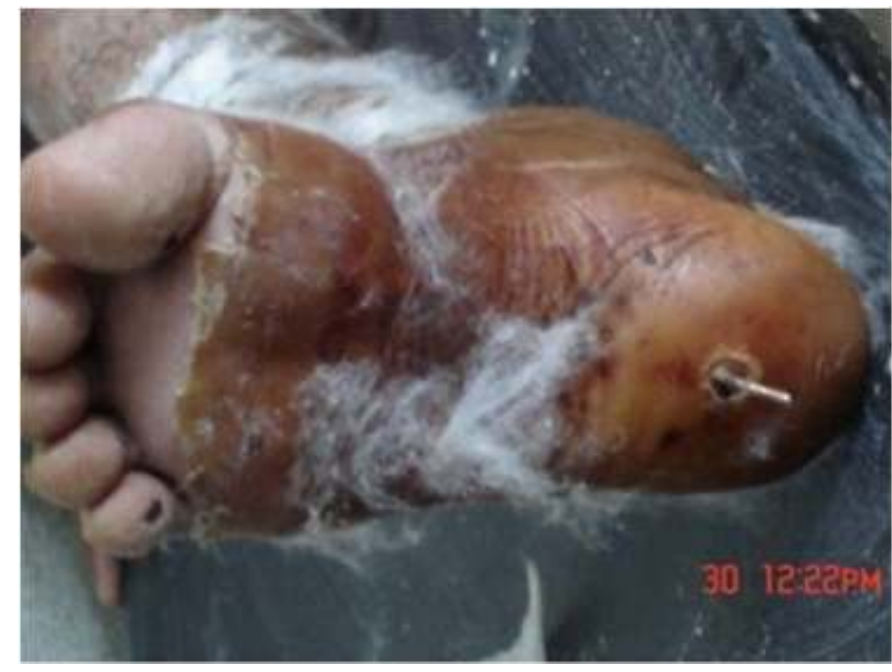

Figure 4 Example 2 - Case 4 (see table 1): Post operative photograph shows the Steinmann pin introduced from plantar surface of heel which is removed prior to cast application.

Figures 1-3 shows the first example of a case of a modified Blair fusion in a group III - Hawkins fracture dislocation. Here, the dislocated part of the body of the talus was excised. The gap between calcaneus and tibia was filled with cancellous bone taken from lower tibia, anterior surface from the bed of sliding cortical graft and ipsilateral iliac crest. Remaining steps of the surgical procedure were almost same like those of Morris modification of Blair fusion i.e. one cortical screw was used to fix the sliding graft and thick $\mathrm{K}$-wire of $2.5 \mathrm{~mm}$ diameter was used instead of Steinmann pin.

The operation was performed by exposing the ankle through 'universal incision' to foot and ankle (i.e. antero-lateral approach.) Incision was started at the upper end from eight to ten centimeters above the ankle joint and extended distally and end at the base of the fourth metatarsal. Incision was made over the fascia and the superior and inferior extensor retinacula down to the periosteum of the tibia and the capsule of the ankle joint. This dissection usually divides the anterolateral malleolar and lateral tarsal arteries.

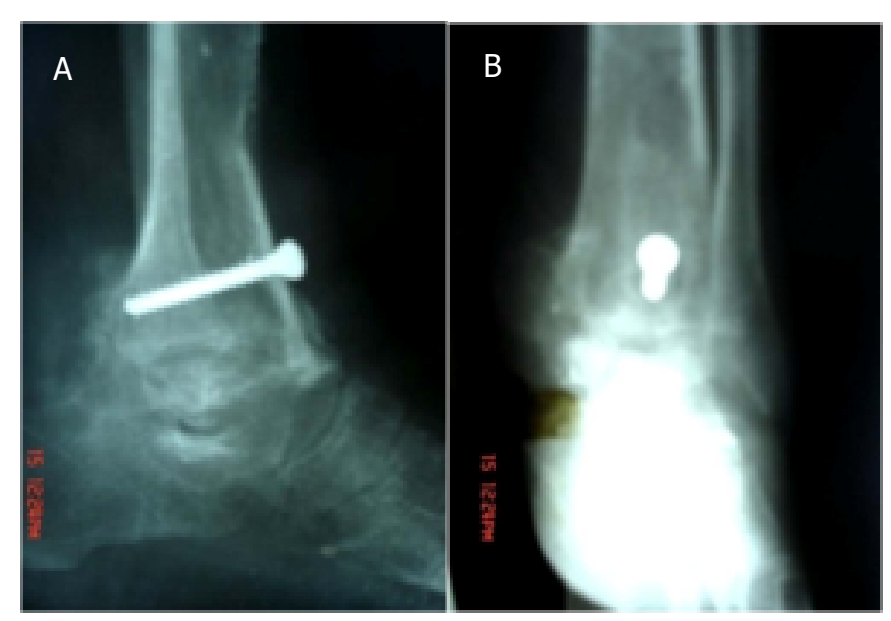

Figure 5A and 5B Example 2 - Case 4 (see table 1): Post operative radiographs show advanced fusion and nice graft incorporation lateral $(A)$ and anteroposterior (B) views.

Cutaneous nerves were identified and protected. Extensor digitorum brevis muscle was detached from its origin and reflected distally. Extensor tendons, the dorsalis pedis artery and the deep peroneal nerve were retracted medially and the capsule was incised to expose the ankle.

With the joint widely exposed, dislocated talar body was excised with an osteotome or nibbled out and the head and neck was left undisturbed. The talonavicular joint and anterior and medial portions of the talocalcaneal joint were untouched. A sliding graft 2.0 by 6.0 centimeters was sliced from the distal anterior portion of the tibia with the help of a thin power saw. This graft was placed into a notch of approximately two centimeters deep made into the neck of the talus. The ankle was held in roughly 10 to 15 degrees of plantarflexion while the graft was fit into the neck of the talus. The graft was fixed with a cortical screw of $4.5 \mathrm{~mm}$ diameter with lower tibia and a thick K-wire of $2.5 \mathrm{~mm}$ diameter was inserted through the plantar aspect of the heel traversing the calcaneus and extending into the medullary canal of the tibia for 10 -12 centimeters. 


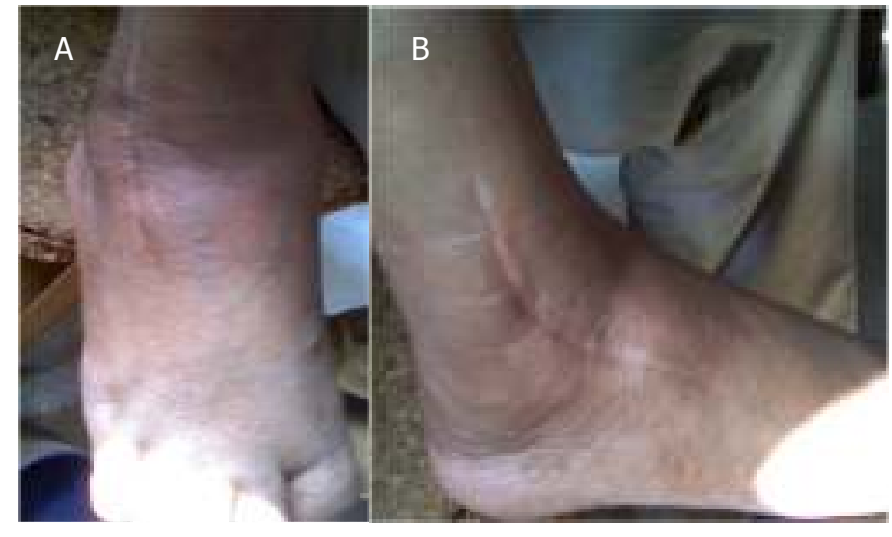

Figure 6A and 6B Example 2 - Case 4 (see table 1): Post operative Photographs shows healed Antero-Lateral incision, anterior view (A) and lateral view (B), started 8 to $10 \mathrm{~cm}$ above the ankle and extended downwards over the joint and in the line of fourth metatarsal bone more distally over foot.

Cancellous graft was packed around the fusion site. Graft was harvested from bed of the sliding graft or ipsilateral iliac crest. Subjects have given informed consent, and that the study has been approved by an institutional review board. A below knee plaster slab was applied after surgery for better soft tissue healing. Cast was substituted after stitch removal and K-wires were routinely taken out after four weeks of surgery. (Figures 4, 5A, 5B, 6A and 6B) Non -weight bearing crutch walking was continued up to almost 12 weeks after surgery. They were followed up at monthly interval for one year.

From second year onwards patients were followed up at every six months in Outpatient Department. The operated ankle was assessed with serial roentgenograms to look for progress of fusion with proper bony alignment and measurement of tibiopedal movement. Tibiopedal motion is defined as the curve of motion between maximum dorsiflexion and maximum plantarflexion of ankle and the angles were subtended by the long axis of the tibia and that of the foot in the lateral projection. The range of tibiopedal motion was measured with use of a goniometer between the axis of the tibia and the foot in positions of maximum dorsiflexion and plantarflexion.
In our study, results were considered excellent if the patient had completely asymptomatic foot and ankle and comfortable in Activities of Daily Life (ADL) and if tibiopedal movement ranged from 15 to 20 degrees. If there was occasional discomfort which caused no restriction in ADL and tibiopedal movement ranged from 10 to 15 degrees, then results were considered good. Poor result was with less than 10 degree tibiopedal movement and painful ankle to limit ADL.

\section{Results}

According to the above mentioned protocol all five patients were followed up and evaluated after surgery. Mean age of patients in this series was twenty nine years. Right sided ankles were more commonly affected here (4:1). Roughly 4 months was required for bony fusion to take place. (range 3 - 6months)

Three cases out of five were considered as with excellent outcome, two were with good outcome after follow up according to the mentioned criteria.

Tibiopedal movement was 15 to 20 degrees in three cases and 10 to 15 degrees in one case and lower than 10 degree in one case. Sound fusion took place in four cases. In one case fusion was not sound, so it was painful on walking. It was with poor outcome. Another case with good result had occasional discomfort in ankle though there was solid bony fusion. Patient who had compound Group- III fracture dislocation had poor outcome in follow up. It was possibly due to formation of fibrosis from infected tissues inside even after thorough primary wound clearance and formation of pseudoarthrosis at fusion site. But heel height and shape was maintained in all cases. Inversion and eversion was partially restricted in all patients.

Antero lateral incision easily and widely exposed the ankle without any neurovascular injury. It could be freely extended upwards or downwards to fulfill the requirement during surgery. In one case posterolateral exposure was also necessary for removal of posteriorly dislocated body of the talus in addition to standard anterolateral incision. Table 1 shows the details of all five cases of this series. 


\begin{tabular}{|c|c|c|c|c|c|c|c|}
\hline Case & Age/Sex & $\begin{array}{l}\text { Type of fracture Init } \\
\text { (Hawkins) }\end{array}$ & itial treatment Time $\mathrm{f}$ & injury to fusion & $\begin{array}{l}\text { Months of } \\
\text { follow-up }\end{array}$ & $\begin{array}{l}\text { Range of } \\
\text { movements } \\
\text { (Tibiopedal } \\
\text { movement) }\end{array}$ & Result \\
\hline 1 & $24 / \mathrm{M}$ & Group III,closed & Close manipulation & 15days & 28 & 18 & Excellent \\
\hline 2. & $30 / \mathrm{F}$ & $\begin{array}{c}\text { Group III with } \\
\text { \#body of talus,closed }\end{array}$ & Plaster & 17 days & 30 & 12 & Good \\
\hline 3. & $36 / \mathrm{M}$ & Group III ,compound & $\mathrm{d}$ wound debridement & 17 days & 24 & 8 & poor \\
\hline 4. & $40 / \mathrm{M}$ & Group III,closed & Close manipulation & 10days & 26 & 20 & Excellent \\
\hline 5 & $26 / M$ & Group III,closed & Close manipulation & 14 days & 35 & 18 & Excellent \\
\hline
\end{tabular}

Table 1 This table compares basic descriptive information of five cases with a Hawkins Group III fracture-dislocation of neck of talus treated with Modified Blair arthrodesis. They were followed up for two to three years. Three out of five patients had an excellent result.

\section{Discussion}

Fracture of the neck of the talus, treated with Blair fusion or with its different modifications, has been published in few journals in different times. But it has not been discussed and published at many places as it deserves .In the reported series five cases of Hawkins Group III were operated with modified Blair's fusion.

In 1943, Blair used a distal tibial sliding cortical graft without fixation in two patients with acute fracture of the neck of the talus. At the time of follow-up (minimum, four months), both fractures had united in follow-up (minimum, four months). ${ }^{3}$ Morris et al., in 1971 modified the procedure .They used a cortical screw up to posterior cortex of tibia to fix the sliding graft and a Steinmann pin introduced through planter surface of heel traversing calcaneus into the tibia by 10 to 12 centimeters. Four of their ten patients had a talar fracture with avascular necrosis, and six had an acute fracture. Seven had an excellent result and three, a good result. ${ }^{9}$ Later, Morris reported a series of four patients with a minimum two months follow-up after modified Blair procedure for the treatment of a fracture and osteonecrosis. ${ }^{10}$ Result was excellent in those two cases.
MD Dennis and HS Tullos, in 1980 ,performed a retrospective clinical and roentgenographic study on seven patients who underwent Blair tibiotalar arthrodesis with the average follow-up was 3.9 years. Results were good in five patients, fair in one, and poor in one. In two patients, pseudoarthrosis developed: painful in one and asymptomatic in one. ${ }^{11}$

In 1982, Lionberger, et al., described arthrodesis of the distal aspect of the tibia to the talar neck with use of a pediatric hip-compression screw. Five patients were treated and followed up for a mean of one year, one developed a delayed union. ${ }^{12}$ Canale and Kelly reported a series of seventy-one fractures through the neck of the talus. Blair procedure was used for two fractures but both had poor result. ${ }^{13}$

In the reported series five cases were included. All five cases were categorized as Hawkins Group- III. (i.e. fracture of neck of the talus with dislocation of talo-tibial joint and subtalar joint, full displacement of the body of the talus from ankle) Fractures were treated with primary modified Blair arthrodesis because there was 75 to 100 percent chance of development of avascular necrosis of the body of the talus after this type of fracture-dislocation according to several reports. 
Morris and associates, in 1971 advocated immediate excision of the extruded body for patients with comminuted fractures of the talar body as well as those with closed Group- III fracture-dislocation of talar neck since avascular necrosis occurs in over 90 per cent of these injuries. In this reported series, the modification was also after those of Morris. (i.e. one cortical screw and one thick k-wire were used)

In contrary to the modification presented by Morris, the body of the talus was partially excised in this study group with the hope that remained cortical bone with added cancellous bone from lower tibia would make sound fusion with maintenance of height of the heel. $\mathrm{K}$-wire inserted through calcaneus into the tibia enhanced the stabilization of ankle construct for first four weeks. That helped the fusion process to take place initially.

Most of our patients had a successful clinical result with high rate of union, in spite of the complex nature of their problems. Three cases out of five $(60 \%)$ were considered as excellent, one was with good $(20 \%)$ and one $(20 \%)$ was with poor outcome after follow up of almost two years. Tibiopedal movement was 15 to 20 degrees in three cases and 10 to 15 degrees in one and less than 10 degrees in one case. Fusion took place in all cases. Two cases had occasional discomfort in ankle though there was solid bony fusion. Heel height and shape was maintained in all cases.

In essence, a modified Blair arthrodesis may be opted for patients who have Hawkin's Group III fracturedislocation. It has the advantage over tibiocalcaneal arthrodesis of giving a normal-appearing foot, producing no shortening, and allowing motion to remain at the talonavicular and anterior subtalar joints thus helping the patients to walk with comfort.

\section{Conclusion}

Modified Blair fusion may be recommended for fracture of the neck of the talus with dislocation of talar body, as it is a relatively easy way out of a complex problem around the ankle. As avascular necrosis of talar body after Group III fracturedislocation takes place in almost all cases, primary osteosynthesis has practically no role in management. Postoperative tibiopedal movement also helps the patient to walk more physiologically. Above all, heel height and shape is maintained after Blair fusion, so patients usually enjoy well fitted shoe.

\section{References}

1. Miller 0L, Baker LD. Fracture and fracture-dislocation of the astragalus. Southern Med J 1939 32: 125-136.

2. Schrock RD, Johnson HE, Waters CH, Jr. Fractures and fracture-dislocations of astragalus (talus). JBJS 1942 24A: 560573.

3. Blair HC. Comminuted fractures and fracture dislocations of the body of the astragalus. Operative treatment. Am J Surg1943. 59: 37-47.

4. Detenbeck LC, Kelly PJ. Total dislocation of the talus. JBJS 1969 51A: 283-288.

5. Hawkins LG. Fractures of the neck of the talus. JBJS 1970 52A: 991-1002.

6. Colart WD. “Aviator's Astragalus”. JBJS 1952 34B: 545-566.

7. Kenwright J, Taylor R0. Major injuries of the talus. JBJS 1970 52B: 36-48.

8. Pennal GF. Fractures of the talus. Clin Orthop1963 30: 53-63. 9. Morris HD, Hand WL, Dunn AW. The modified Blair fusion for fractures of the talus. JBJS 1971 53A: 1289-1297.

10. Morris HD. Aseptic necrosis of the talus following injury. Orthop Clin North America 1974 5: 177-189.

11. Dennis MD, Tullos HS. Blair tibiotalar arthrodesis for injuries to the talus. JBJS 1980 62A: 103-107.

12. Lionberger DR, Bishop JO, Tullos HS. The modified Blair fusion. Foot and Ankle 1982. 3: 60-62.

13. Canale ST, Kelly, FB Jr. Fractures of the neck of the talus. Long-term evaluation of seventy-one cases. JBJS 1978 60A: 143156. 